\section{EFFECT OF POLYMYXIN B ON THE FATTY ACID COMPOSITIONS OF OUTER MEMBRANES FROM SERRATIA MARCESCENS}

Sir:

The binding ability of cationic polymyxin B (PB) with anionic components such as lipopolysaccharide (LPS) and phospholipids (PL) in outer membranes of gram-negative bacteria has been studied, ${ }^{1)}$ and the complexes formed have been characterized. ${ }^{2,3)}$ In addition, the degradative effect of PB on $\mathbf{L P S}^{2,4)}$ and $\mathbf{P L}^{5)}$ have also been demonstrated. In the case of phospholipid degradation, KusAno et al. ${ }^{6)}$ attributed the degradative effect of PB to its activation of a phospholipase system. Since a phospholipase $\mathrm{A}_{1}$ has been shown to exist in the outer membranes of gramnegative bacteria, ${ }^{7)}$ it seems feasible to study the damage effect of $\mathrm{PB}$ on outer membranes of gram-negative bacteria by analysing the fatty acid compositions of the outer membrane lipids isolated from cells after PB treatment. In this communication, we report the results of the fatty acid analysis of the extractable and bound lipids in outer membranes of Serratia marcescens before and after PB treatment.

\section{Materials and Methods}

The strains of $S$. marcescens used in this study have been previously described. ${ }^{2}$ ) Cells were grown in an enriched medium with aeration at room temperature and harvested at an optical density between 0.50 and 0.55 units.

Outer membranes were isolated according to a slightly modified method of OsBorn and MunsoN. ${ }^{7)}$ In general the method involves the formation of spheroplast of cells washed with Tris buffer by treatment with lysozyme-EDTA in a sucrose Tris buffer solution, and sucrose density gradient centrifugation of the sonified spheroplasts. The outer membrane fractions were recovered from the high density region.

The in vivo treatment of the outer membrane is the same as that used for the in vivo treatment of whole cells. ${ }^{8)}$ Cells from 1 liter of culture medium were treated with $20 \mathrm{mg}$ of PB (Burroughs Wellcome) in $75 \mathrm{ml}$ of $0.9 \% \mathrm{NaCl}$ solution, $\mathrm{pH} 7.3$ for 1 minute at $37^{\circ} \mathrm{C}$. Outer membranes were isolated from the treated cells.

Total extractable lipids (TEL) were extracted with chloroform-methanol $(2: 1, \mathrm{v} / \mathrm{v})$ as previously described. ${ }^{9)}$ The yields of TEL were determined gravimetrically. Both TEL and the bound lipids (in the residue of the extracted outer membranes) were hydrolysed in $6 \mathrm{~N} \mathrm{HCl}$ for 24 hours, and the released fatty acids converted into methyl esters for gas chromatographic analysis. ${ }^{9)}$

\section{Results and Discussion}

Table 1 shows the yields and the fatty acid compositions of the TEL from outer membranes of various strains of $S$. marcescens before and after PB treatment. The degradative effect of PB on outer membranes of $S$. marcescens is clearly shown by the significant decrease $(17 \sim 42 \%)$ in the yields of the TEL. The fatty acid compositions of the TEL of the outer membranes isolated from cells before and after PB treatment differed more quantitatively than qualitatively. In both instances, the outer membranes of $S$. marcescens were enriched in saturated $\left(\mathrm{C}_{16}\right)$ and monounsaturated $\left(\mathrm{C}_{18: 1}\right)$ fatty acids, with more saturated in the resistant strains (08 and 6292) and more monounsaturated in the sensitive strains (Bizio and 13378). An explanation for the high saturated fatty acid contents of TEL of outer membranes could be due to the relatively high amount of phosphatidylethanolamine in these membranes. ${ }^{10)}$ This phospholipid contains more saturated fatty acids than phosphatidylglycerol and diphosphatidylglycerol which are predominant in the cytoplasmic membranes. The significant decrease of both the yields of the TEL and the saturated fatty acids after PB treatment not only supports the finding of KUSANO et al. ${ }^{5,6}$ ) on the in vivo activation of a phospholipase system by $\mathrm{PB}$ but also agrees with other reports ${ }^{7)}$ that the phospholipase in the outer membrane of $S$. marcescens and other gram-negative bacteria is the phospholipase $A_{1}$ which generally cleaves the saturated fatty acids located in the alpha position. The lower saturated/unsaturated fatty acid ratio in the TEL of the outer membranes of the sensitive cells before and after PB treatment might indicate that a decrease of hydrophobicity of the membrane lipids may cause an increase in the permeability of a cationic antibiotic such as PB. However, penetration of $\mathrm{PB}$ across the outer membranes of gram-negative bacteria is complicated by the presence of the LPS molecules which not only form complexes with $\mathrm{PB}^{2)}$ but are also degraded by 
Table 1. Yield and fatty acid composition of total extractable lipids in outer membranes of Serratia marcescens, before and after polymyxin B treatment

\begin{tabular}{r|l|c|c|c|c|c|c|c|c|c|c|c|c}
\hline & \multicolumn{1}{|c|}{ Strain } & $\begin{array}{c}\text { Yield of } \\
\text { TEL (\%) }\end{array}$ & $\mathrm{C}_{10}$ & $\mathrm{C}_{12}$ & $\mathrm{C}_{14}$ & $\mathrm{C}_{16}$ & $\mathrm{C}_{16: 1}$ & $\mathrm{C}_{17}$ & $\mathrm{U}^{\mathrm{a}}$ & $\mathrm{C}_{18}$ & $\mathrm{C}_{18: 1}$ & $\mathrm{C}_{19}$ & $\begin{array}{l}\text { aSat/ } \\
\text { unsat }\end{array}$ \\
\hline \multirow{5}{*}{ Resistant } & $08^{\mathrm{a}}$ & 40.0 & $\mathrm{~T}$ & 2.5 & 4.4 & 69.4 & 0.5 & $\mathrm{~T}$ & 2.9 & 7.3 & 13.0 & $\mathrm{Neg}^{\mathrm{c}}$ & 6.2 \\
& $08-\mathrm{PB}^{\mathrm{b}}$ & 23.0 & $\mathrm{~T}$ & 1.9 & 2.6 & 48.7 & 13.1 & $\mathrm{Neg}$ & 4.8 & 5.9 & 14.7 & 8.2 & 2.1 \\
& 6292 & 35.0 & $\mathrm{~T}$ & 1.9 & 6.3 & 62.8 & 5.6 & 3.2 & 7.5 & 2.8 & 9.9 & $\mathrm{Neg}$ & 5.0 \\
& $6292-\mathrm{PB}$ & 23.4 & $\mathrm{~T}$ & 1.6 & 3.9 & 44.0 & 14.3 & $\mathrm{~T}$ & 3.4 & 7.1 & 18.9 & 6.8 & 1.7 \\
\hline \multirow{5}{*}{ Sensitive } & Bizio & 51.0 & 6.5 & 2.8 & 9.5 & 45.1 & $\mathrm{~T}$ & 7.1 & 2.3 & 4.2 & 22.8 & $\mathrm{Neg}$ & 3.3 \\
& Bizio-PB & 36.6 & $\mathrm{~T}$ & 2.6 & 3.7 & 46.4 & $\mathrm{~T}$ & $\mathrm{~T}$ & 2.0 & 3.0 & 36.3 & 4.2 & 1.5 \\
& 13378 & 44.3 & $\mathrm{~T}$ & 3.5 & 7.3 & 47.0 & 2.7 & $\mathrm{Neg}$ & 5.3 & 5.9 & 28.4 & $\mathrm{Neg}$ & 2.0 \\
& $13378-\mathrm{PB}$ & 36.5 & $\mathrm{~T}$ & 1.9 & 3.5 & 34.1 & 8.6 & $\mathrm{Neg}$ & 2.3 & 2.8 & 4.15 & 5.4 & 0.8 \\
\hline
\end{tabular}

a Outer membranes isolated from untreated whole cells.

b Outer membranes isolated from PB treated whole cells.

c $\mathrm{Neg}=$ negative.

d A ratio of saturated fatty acids versus unsaturated fatty acids. Values do not include the unknown and $\mathrm{C}_{19}$.

e $\mathrm{U}=$ unidentified component.

Table 2. Fatty acid composition of bound lipids in outer membranes of $S$. marcescens, before and after polymyxin $\mathrm{B}$ treatment

\begin{tabular}{l|l|r|r|r|r|r|r|r|r|c|c}
\hline & \multicolumn{1}{|c|}{ Strain } & $\mathrm{C}_{12}$ & $\mathrm{C}_{14}$ & $\mathrm{U}_{1}^{\mathrm{d}}$ & $\mathrm{C}_{16}$ & $\mathrm{C}_{16: 1}$ & $\mathrm{C}_{17}$ & $\mathrm{U}_{2}^{\mathrm{d}}$ & $\mathrm{C}_{18}$ & $\mathrm{C}_{18: 1}$ & $\mathrm{C}_{14-\mathrm{OH}}$ \\
\hline \multirow{3}{*}{ Resistant } & $08^{\mathrm{a}}$ & 7.7 & 24.3 & 11.0 & 35.1 & $\mathrm{~T}$ & $\mathrm{Neg}^{\mathrm{c}}$ & 5.2 & 1.7 & 1.9 & 13.0 \\
& $08-\mathrm{PB}^{\mathrm{b}}$ & 11.3 & 19.8 & 3.4 & 38.2 & 1.6 & $\mathrm{Neg}$ & 3.3 & 5.6 & $\mathrm{Neg}$ & 16.9 \\
& 6292 & 15.2 & 23.4 & 5.2 & 26.8 & 1.7 & $\mathrm{Neg}$ & 6.8 & 3.7 & $\mathrm{Neg}$ & 17.3 \\
& $6292-\mathrm{PB}$ & 10.0 & 24.1 & 5.0 & 25.7 & 3.4 & 1.6 & 5.5 & $\mathrm{~T}$ & $\mathrm{~T}$ & 17.4 \\
\hline \multirow{5}{*}{ Sensitive } & Bizio & 11.3 & 16.4 & 5.0 & 36.5 & $\mathrm{~T}$ & $\mathrm{Neg}$ & 2.3 & 10.6 & $\mathrm{Neg}$ & 17.8 \\
& Bizio-PB & 14.0 & 17.8 & 4.4 & 34.1 & 3.5 & $\mathrm{Neg}$ & 7.7 & 2.3 & $\mathrm{Neg}$ & 16.2 \\
& 13378 & 11.7 & 17.0 & 2.7 & 28.7 & 5.7 & 3.1 & 9.0 & 2.7 & $\mathrm{~T}$ & 19.4 \\
& $13378-\mathrm{PB}$ & 18.6 & 24.7 & 4.6 & 25.5 & 1.1 & 2.8 & 6.2 & 4.1 & 2.3 & 10.2 \\
\hline
\end{tabular}

a Outer membranes isolated from untreated whole cells.

b Outer membranes isolated from PB treated whole cells.

c $\mathrm{Neg}=$ negative.

d $\quad \mathrm{U}=$ unidentified component; $\mathrm{U}_{1}=$ unidentified component 1; $\mathrm{U}_{2}=$ unidentified conponent 2.

PB. ${ }^{4)}$ Hydrophobic interaction of the acyl group of PB with the lipid A moiety of the LPS can cause inactivation of endotoxin (LPS-protein complex $)^{11)}$ as well as facilitating the penetration of the antibiotic through the hydrophobic interior of the outer membrane.

In order to study the effect of PB on lipid A of the LPS of $S$. marcescens, the fatty acid composition of the bound lipids of the outer membranes before and after PB treatment were analysed (Table 2). The fatty acid compositions of the bound lipids resemble those of the $\operatorname{LPS}^{9)}$ and the lipid A. ${ }^{12)}$ The major fatty acids identified were $C_{12}, C_{14}, C_{16}$, and beta-hydroxy $C_{14}$. After PB treatment there was little change in the over- all composition. It can be concluded that TEL is the site of the damage caused by PB treatment which most probably activates the phospholipase $\mathrm{A}_{1}$ system in the outer membranes of $S$. marcescens and other gram-negative bacteria.

Acknowledgement

This investigation is supported in part by a grant from Illinois State University Research Committee.
DAVID A. BRown
JoSEPH C. TSANG*
Departments of Chemistry* and Biological Sciences Illinois State University Normal, Illinois 61761, U.S.A. (Received November 22, 1976) 


\section{References}

1) Teuber, M. \& J. Bader: Action of polymyxin $\mathrm{B}$ on bacterial membranes. Binding capacities for polymyxin B of inner and outer membranes isolated from Salmonella typhimurium G30. Arch. Microbiol. 109: 51 58, 1976

2) Tsang, J. C.; D. A. Weber \& D. A. Brown: Evidences for complex formation between polymyxin B and lipopolysaccharides from Serratia marcescens. J. Antibiotics 29: $735 \sim 742,1976$

3) Teuber, M.: Action of polymyxin B on bacterial membranes. II. Formation of lipophilic complexes with phosphatidic acid and phosphatidylglycerol. Z. Naturforsch. 28c: 476 477, 1973

4) Lopes, J. \& W. E. INNISS: Electron microscopy of effects of polymyxin B on Escherichia lipopolysaccharide. J. Bact. 100: 1128 1130, 1969

5) Kusano, T.; K. Izaki \& H. Takahashi: Degradation of phospholipid in Pseudomonas aeruginosa induced by polymyxin B. J. Antibiotics 28: 689 695, 1975

6) Kusano, T.; K. IzaKi \& H. TAKahashi: In vivo activation by polymyxin $\mathrm{B}$ of phospholipase from
Pseudomonas aeruginosa and Escherichia coll. J. Antibiotics 29: 674 675, 1976

7) Osborn, M. \& R. Munson: Separation of the inner (cytoplasmic) and outer membranes of gram-negative bacteria: Methods in Enzymology 3: $642 \sim 653,1974$

8) Weber, D. A. \& J. C. TsANG: Immunochemical behavior of lipopolysaccharides from Serratia marcescens after polymyxin B treatment. Microbios Lett. 1: 125 130, 1976

9) Wade, A.; D. A. Brown \& J. C. Tsang: Lipid composition of Serratia marcescens sensitive and resistant to polymyxin B. Microbios 13: 111 121,1975

10) Lugtenberg, E. J. J. \& R. Peters: Distribution of lipids in cytoplasmic and outer membranes of Escherichia coli K12. Biochim. Biophys. Acta 441: 38 47, 1976

11) COOPERSTOCK, M.: Inactivation of endotoxin by polymyxin B. Antimicr. Agents \& Chemoth. 6: $422 \sim 425,1974$

12) Alaupovic, P. A.; A. C. Olson \& J. C. Tsang: Studies on the characterization of lipopolysaccharides from two strains of Serratia marcescens. Ann. N.Y. Acad. Sci. 133: 546 565, 1966 